\section{Anaesthesia in lateral position for spinal surgery in pregnant female: Case report and review of literature}

\section{Shobha Purohit ${ }^{1}$, Saurabh Jain, Radhey S. Mittal}

Surgery during pregnancy is complicated by the need to balance the requirements of both the mother and the foetus. Surgery is only conducted during pregnancy when it is absolutely necessary for the well being of the mother, foetus or both. Regional anaesthesia is usually preferred in pregnancy whenever possible. Regional anaesthesia minimises foetal drug exposure, airway management is simplified, blood loss may be decreased and overall risks to the mother and foetus are less. The largest risk of regional anaesthesia is hypotension resulting from sympathetic nerve blockade, which reduces uterine blood flow and perfusion to the foetus. Attention to maternal fluid volume and blood pressure is critical. When surgery is indicated during pregnancy, maintenance of maternal oxygenation, perfusion and homeostasis with the minimal dose of anaesthesia required will assure the best outcome for the foetus. Achieving these goals will be more difficult when surgery has to be done in unconventional positions with an ongoing debilitating illness. We describe the anaesthetic management of a case of a pregnant woman with Pott's spine.

A 28-year-old pregnant female at 20 weeks of gestation presented with progressive parapresis with bladder involvement. She was a diagnosed case of pulmonary tuberculosis (TB). She was receiving anti-TB treatment but her compliance was poor. Magnetic resonance imaging of her spine showed a D7 D8 Pott's spine with epidural collection compressing the spinal cord. In view of the worsening neurological condition it was decided to perform a costo-transversectomy of D8, drainage of epidural collection with debridement and decompression of spinal cord in lateral position. Ultrasonography of the abdomen confirmed the 22 weeks gravid uterus with single live foetus with cardiac activity without any sign of growth retardation or congenital anomaly. Obstetric consultation regarding the surgery and preoperative obstetric management was obtained. A written and informed consent for the possibility of foetus loss during the procedure was taken. Anaesthetic care was directed at ensuring optimal maternal and foetal well being Standard monitoring was established with electrocardiogram, arterial blood pressure, oxygen saturation, end tidal $\mathrm{CO} 2$ and invasive BP. Anaesthesia was induced with Propofol $(2 \mathrm{mg} / \mathrm{kg}$ ) and Remifentanil $(0.1 \mu \mathrm{g} / \mathrm{kg} / \mathrm{min})$. Succinylcholine $(1 \mathrm{mg} / \mathrm{kg})$ was administered to facilitate tracheal intubation. Anaesthesia was maintained with Remifentanil $(0.1-0.2 \mu \mathrm{g} / \mathrm{kg} / \mathrm{min})$ and Propofol $(4-8 \mathrm{mg} / \mathrm{kg} / \mathrm{h})$ infusion with air/O2 (\%50-50) along with muscle paralysis using Rocuronium ( $0.6 \mathrm{mg} / \mathrm{kg}$ bolus followed by $10 \mathrm{mcg} / \mathrm{kg} / \mathrm{min}$ infusion). The lungs were mechanically ventilated to maintain mild hypocapnia (end-expiratory $\mathrm{CO}_{2}$ approximately $33 \mathrm{mmHg}$ ). Patient was monitored in accordance with American Society of Anesthesiologists guidelines and invasive BP monitoring. Foetal heart sounds were monitored by obstetrician with the help of a stethoscope. The estimated blood loss was $200 \mathrm{ml}$. Patient was given $1000 \mathrm{ml}$ of intravenous fluid for replacing the $400 \mathrm{ml}$ urine $+200 \mathrm{ml}$ of blood for this 2-h long surgery. The rest of intra-operative period was uneventful. Following the completion of surgical procedures, the trachea was extubated during deep plane of anaesthesia. The patient promptly emerged from anaesthesia. However, she regained power slowly. The motor power improved by one MRC grade. Post-operative ultrasonography showed one live foetus with satisfactory parameters. Patient was kept under observation for the next 7 days. She was discharged with on $8^{\text {th }}$ day without any complication. On follow up patient delivered a healthy baby on 36 weeks of gestational age without any congenital anomaly.

It is estimated that some $1-2 \%$ of pregnant women in developed countries receive anaesthesia during their pregnancy for surgery unrelated to the delivery. ${ }^{[1]}$ Between the $15^{\text {th }}$ and $56^{\text {th }}$ day of gestation, the human embryo is said to be most vulnerable to the teratogenic effects of a drug ${ }^{[2]}$ Studies of outcomes in large numbers of women who underwent surgery during pregnancy suggest no increase in congenital abnormalities but a greater risk of abortion, growth restriction and low birth weight. These studies concluded that problems resulted from primary disease or the surgical procedure itself rather than exposure to anaesthesia. ${ }^{[3]}$

A multidisciplinary approach needs to be established early in the management. If possible, surgery should be delayed until the second trimester. Elective surgery should not be performed.

Departments of Neurosurgery and ${ }^{1}$ Anaesthesia, Sawai Man Singh Medical College and Hospital, Jaipur, Rajasthan, India

Address for correspondence:

Dr. Saurabh Jain, 33, Uniara Gardens, Near Trimurti Circle, JLN Marg, Jaipur, Rajasthan, India. E-mail: drsaurabh_jain@rediffmail.com 


\section{REFERENCES}

1. Crowhurst JA. Anaesthesia for non-obstetric surgery during pregnancy. Acta Anaesthesiol Belg 2002;53:295-7.

2. Goodman S. Anaesthesia for non obstetric surgery in the pregnant patient. Semin Perinatol 2002;26:136-45.

3. Mazze RI, Kallen B. Reproductive outcome after anaesthesia and operation during pregnancy: A registry study of 5405 cases. Am J Obstet Gynecol 1989;161:1178-85.

\begin{tabular}{|l|l|}
\hline \multicolumn{2}{|c|}{ Access this article online } \\
\hline Quick Response Code: & Website: \\
\hline & www.jnaccjournal.org \\
\cline { 2 - 3 } & \\
\hline
\end{tabular}

